\title{
Osteoporose e saúde bucal: revisão de literatura
}

\author{
Osteoporosis and oral health: literature review \\ Osteoporosis y salud bucal: revisión de la literatura
}

Recebido: 07/11/2021 | Revisado: 12/11/2021 | Aceito: 16/11/2021 | Publicado: 26/11/2021

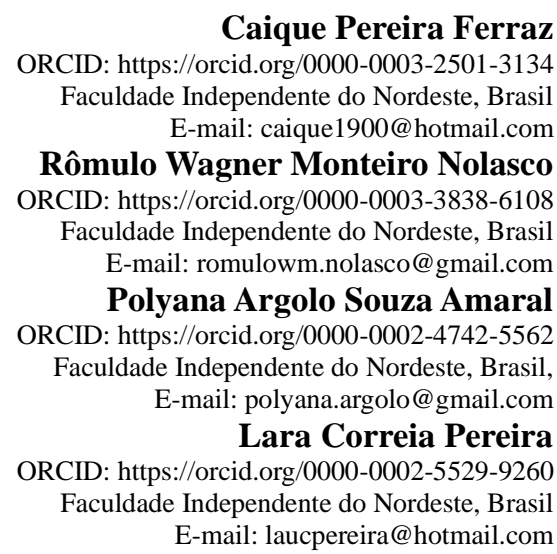

\begin{abstract}
Resumo
A osteoporose é caracterizada pela perda de massa óssea e deterioração da microarquitetura do tecido ósseo e, consequentemente fragilidade óssea. $\mathrm{O}$ osso acometido por essa doença pode ser encontrado na maxila e mandíbula influenciando diversos procedimentos odontológicos. Nesse contexto, a avaliação do desgaste ósseo utilizando recursos imaginológicos para investigação da densidade e do conteúdo mineral ósseo é essencial. O presente trabalho tem como objetivo realizar uma revisão de literatura sobre a relação entre a osteoporose e seus impactos na saúde bucal. Para a operacionalização da revisão utilizou-se dos seguintes descritores: osteoporose, saúde bucal e idoso com o operador booleano AND, de acordo com as bases de dados: BVS, LILACS, SciELO e PubMed, nos idiomas inglês e português. Havendo uma escassez em encontrar trabalhos que aborde o tema, o que demonstra a necessidade de maiores estudos sobre o assunto. Diante disso, dezenove artigos foram selecionados para a elaboração da revisão. Conclui-se que é necessário identificar os fatores que predispõem a um risco aumentado para atuar de modo preventivo a fim de obter desfechos clínicos positivos. Sendo assim, é extremamente necessário que se realize estudos para identificar maiores relações da Osteoporose e Osteopenia com as alterações na cavidade Oral e suas repercussões clínicas.
\end{abstract}

Palavras-chave: Osteoporose; Saúde bucal; Idoso.

\begin{abstract}
Osteoporosis is characterized by loss of bone mass and deterioration of bone tissue microarchitecture and, consequently, bone fragility. The bone affected by this disease can be found in the maxilla and mandible, influencing several dental procedures. In this context, the assessment of bone wear using radiological resources to investigate bone density and mineral content is essential. This work aims to carry out a literature review on the relationship between osteoporosis and its impacts on oral health. For the operationalization of the review, the following descriptors were used: osteoporosis, oral health and elderly with the Boolean operator AND, according to the databases: BVS, LILACS, SciELO and PubMed. There is a shortage of finding papers that address the topic, which demonstrates the need for further studies on the subject. Therefore, nineteen articles were selected for the preparation of the review. It is concluded that it is necessary to identify the factors that predispose to an increased risk (menopausal women, vitamin D deficiency, osteoporotic elderly and diabetes mellitus) in order to act preventively in order to obtain positive clinical outcomes. Therefore, it is extremely necessary to carry out studies to identify greater relationships between Osteoporosis and Osteopenia with changes in the Oral cavity and their clinical repercussions.
\end{abstract}

Keywords: Osteoporosis; Oral health; Old man.

\section{Resumen}

La osteoporosis se caracteriza por la pérdida de masa ósea y el deterioro de la microarquitectura del tejido óseo y, en consecuencia, la fragilidad ósea. El hueso afectado por esta enfermedad se puede encontrar en el maxilar y la mandíbula, influyendo en varios procedimientos dentales. En este contexto, la evaluación del desgaste óseo utilizando recursos radiológicos para investigar la densidad ósea y el contenido mineral es fundamental. Este trabajo tiene como 
objetivo realizar una revisión de la literatura sobre la relación entre la osteoporosis y sus impactos en la salud bucal. Para la operacionalización de la revisión se utilizaron los siguientes descriptores: osteoporosis, salud bucal y anciano con el operador booleano AND, según las bases de datos: BVS, LILACS, SciELO y PubMed. Hay escasez de trabajos de búsqueda que aborden el tema, lo que demuestra la necesidad de realizar más estudios sobre el tema. Por tanto, se seleccionaron diecinueve artículos para la elaboración de la revisión. Se concluye que es necesario identificar los factores que predisponen a un mayor riesgo (mujeres menopáusicas, deficiencia de vitamina $\mathrm{D}$, ancianos osteoporóticos y diabetes mellitus) para actuar de manera preventiva para obtener resultados clínicos positivos. Por tanto, es sumamente necesario realizar estudios para identificar mayores relaciones entre Osteoporosis y Osteopenia con cambios en la cavidad bucal y sus repercusiones clínicas.

Palabras clave: Osteoporosis; Salud bucal; Anciano.

\section{Introdução}

O envelhecimento populacional já é observado no Brasil, de acordo com os dados do Instituto Brasileiro de Geografia e Estatística (IBGE) a população de idosos atingirá cerca de 41,5 milhões de pessoas no ano de 2030 (Meira et al., 2018). No processo de envelhecimento, o organismo passa por algumas transformações, segundo Spezzia (2013), ainda na fase adulta, por volta dos quarenta anos, inicia-se a lenta e progressiva perda óssea. Com o passar dos anos, alterações na cavidade oral são mais relevantes, na saliva observa-se diminuição da quantidade, composição e viscosidade, presença de irregularidades na superfície do cemento e do osso alveolar, alteração quantitativa de tecido mineralizado na cortical e no trabeculado ósseo (Meira et al., 2018; Vargas et al., 2018).

De acordo com Sales, Catão e Neto (2017) a boca reflete as condições vividas pelo idoso, ou seja, além da própria senescência, fatores nutricionais, uso de medicamentos, próteses, hábitos psicopatológicos, alcoolismo, tabagismo e mudanças metabólicas estão associadas a um mau prognóstico na velhice. Ademais, várias doenças sistêmicas podem acometer o sistema estomatognático, acarretando no seu desequilíbrio, dentre elas a doença osteometabólica denominada osteoporose (Vargas et al., 2018).

A osteoporose é caracterizada pela perda de massa óssea e deterioração da microarquitetura do tecido ósseo e, consequentemente, fragilidade óssea (Vargas et al., 2018; Spezzia, 2014). Isso ocorre devido ao impedimento ou retardo da osseointegração através da relação celular inadequada entre osteoblastos e osteoclastos (Vargas et al., 2018; Spezzia, 2014; Pavlesen et al., 2016). Nesse contexto, segundo a Associação Brasileira de Avaliação da Saúde Óssea e Osteometabolismo, cerca de 10 milhões de pessoas convivem com essa doença no Brasil (Associação Brasileira de Avaliação Óssea e Osteometabolismo, 2020).

A maxila e mandíbula podem ser acometidas pela osteoporose, influenciando diversos procedimentos odontológicos como: implantes osseointegrados, exodontia, problemas periodontais e etc. A exemplo da implantodontia, a obtenção de um novo osso em torno da superfície do implante depende diretamente dessa razão celular, e, qualquer alteração pode levar à déficits de massa óssea. Nessas condições o processo de osseointegração estaria prejudicado em ossos osteoporóticos (Vargas et al., 2018; Spezzia, 2014).

A avaliação do desgaste ósseo pode ser visualizada através de métodos de imagem. Nessa perspectiva, recursos radiológicos são fundamentais para a investigação da densidade e do conteúdo mineral ósseo: medidas densitométricas por radiografias periapicais e panorâmicas (Vargas et al., 2018). A densitometria é caracterizada como padrão-ouro pela Organização Mundial de Saúde (OMS), representando o método de maior acurácia e precisão (Spezzia, 2014).

Geralmente, emprega-se a radiografia panorâmica devido a fácil realização, baixo custo, podendo ser solicitada na rotina odontológica sem maiores problemas (Spezzia, 2014). Uma vez reconhecida pelo dentista e feito encaminhamento para o tratamento médico numa fase em que não exista muitos danos ósseos, pode-se ter menos repercussões ou sequelas nos ossos maxilofaciais, reduzindo complicações que podem interferir desfavoravelmente nas condutas clínicas odontológicas (Spezzia, 2014). 
A saúde bucal na população idosa ainda é precária. A assistência pública precisa ser expandida e incrementada aos pacientes idosos e, por isso, é importante que os profissionais de saúde estejam aptos para cuidar desse segmento populacional (Sales, Catão \& Neto, 2017). Portanto, considerando a relevância evidenciada em questão, o objetivo do presente estudo foi realizar uma revisão narrativa da literatura para analisar a relação entre a doença osteometabólica, osteoporose e a saúde bucal em idosos.

\section{Metodologia}

Trata-se de uma revisão de literatura de caráter narrativo que segundo Gil (2010), é desenvolvida a partir de um material já elaborado, constituído principalmente livros e artigos científicos. Sendo assim, o estudo fundamentou-se de dados selecionados de fontes secundárias como trabalhos acadêmicos, monografias, artigos e revistas na língua. O levantamento bibliográfico deu-se através das consultas nas seguintes base de dados: BVS (Biblioteca Virtual em Saúde), LILACS (Literatura Latino-Americana e do Caribe em Ciências da Saúde), SciELO (Scientific Eletronic Library onLine), PubMed, filtrando-se qualitativamente os artigos, utilizando os descritores em saúde (DeCS): Osteoporose (Osteoporosis), Saúde bucal (Oral health), Idosos (Elderly), de forma única ou combinada, usando o descritor booleano "AND".

Foram incluídos artigos científicos, dentro da temática exposta, com a delimitação de período entre 2013 e 2021, onde abordavam a osteoporose e a saúde bucal, com textos completos, disponíveis, publicados na língua portuguesa, inglesa e espanhola. Foram excluídos trabalhos que não abordavam a saúde bucal diante da doença Osteoporose e que não atendessem aos objetivos propostos ou que não estavam de acordo aos critérios de inclusão.

Na operacionalização da revisão, seguiu-se a seguinte ordem: seleção do descritor, estabelecimento dos critérios para a seleção da amostra, leitura criteriosa dos artigos, interpretação dos dados, elaboração dos fichamentos e apresentação da revisão. A partir disso, foi realizada uma análise narrativa dos artigos, na qual foram ordenados de modo a complementar e correlacionar os diversos fatores relacionados à Saúde Bucal e a doença Osteoporose.

\section{Resultados}

A primeira busca foi realizada através da combinação dos seguintes descritores: "Osteoporosis AND Oral Health AND Elderly". Os resultados obtidos da primeira pesquisa foram, respectivamente: 163, 18, 01 e 310 artigos. Após a leitura do título, resumo e aplicação dos critérios de inclusão e exclusão, apenas 14 artigos foram incluídos no projeto.

Diante disso, uma nova pesquisa foi efetuada, utilizando uma nova combinação dos descritores: “Osteoporosis AND Oral Health" os resultados da nova busca foram 19, 02, 00, 34 estudos, sendo incluídos 05 artigos para complementar a revisão de literatura do trabalho. Desse modo, dezenove artigos se enquadraram nos critérios de inclusão e foram selecionados para a elaboração do estudo, a seguir é demonstrado no Quadro 1 os principais resultados encontrados no levantamento bibliográfico deste estudo.

Quadro 1. Resultados do levantamento bibliográfico.

\begin{tabular}{|c|l|l|}
\hline AUTOR/ANO & \multicolumn{1}{|c|}{ TÍTULO DO ARTIGO } & \multicolumn{1}{|c|}{ RESULTADOS } \\
\hline SPEZZIA, 2013. & $\begin{array}{l}\text { Saúde Bucal em idosos com } \\
\text { osteoporose relatos de caso. }\end{array}$ & $\begin{array}{l}\text { Este estudo relata os casos clínicos de 21 pacientes idosos e com osteoporose com idade entre } \\
69 \text { e 83 anos e teve como objetivo avaliar a presença de outras doenças sistêmicas em } \\
\text { concomitância, o estado geral dos dentes, o número de dentes, que cada qual possuía, o grau } \\
\text { ou nível de higienização individual dos pacientes e quantos destes pacientes eram usuários de } \\
\text { próteses totais. Dos 21 pacientes avaliados, 100\% apresentava mau estado geral ao exame } \\
\text { clínicos, 11 pacientes não possuíam dentes, 05 possuíam na faixa de 16 a 25, e 05 pacientes na } \\
\text { faixa de de 02 a 07 dentes. }\end{array}$ \\
\hline SPEZZIA, 2014. & $\begin{array}{l}\text { O papel da Osteoporose na } \\
\text { Odontologia. }\end{array}$ & $\begin{array}{l}\text { O osso osteoporótico pode ser encontrado na maxila, mandíbula devido a osseointegração } \\
\text { prejudicada, a doença influencia em diversos procedimentos odontológicos. Nos pacientes } \\
\text { edêntulos e portadores de Osteoporose a reabsorção óssea alveolar pós-exodontia pode ser } \\
\text { aumentada e tornar-se severa. }\end{array}$ \\
\hline
\end{tabular}




\begin{tabular}{|c|c|c|}
\hline $\begin{array}{l}\text { JONASSON \& } \\
\text { RYTHÉN, } 2016 .\end{array}$ & $\begin{array}{l}\text { Alveolar bone } \begin{array}{r}\text { loss } \\
\text { in } \\
\text { osteoporosis: a loaded } \\
\text { cellular affair? }\end{array}\end{array}$ & $\begin{array}{l}\text { A remodelação óssea ocorre nas superfícies endosteais onde se situam os osteoclastos e } \\
\text { osteoblastos. Mais superfícies significam mais células e remodelação. A taxa de renovação } \\
\text { óssea no processo alveolar mandibular é provavelmente a mais rápida do corpo; assim, os } \\
\text { primeiros sinais de osteoporose podem ser revelados aqui. Hormônios, osteoporose e } \\
\text { envelhecimento influenciam o processo alveolar e os ossos esqueléticos de forma semelhante. } \\
\text { Uma trabeculação esparsa na região dos pré-molares mandibulares (grandes espaços } \\
\text { intertrabeculares e trabéculas finas) é um sinal confiável de osteopenia e um alto risco de } \\
\text { fratura esquelética. }\end{array}$ \\
\hline $\begin{array}{l}\text { MILIUNIENE et } \\
\text { al., } 2016 .\end{array}$ & $\begin{array}{l}\text { Evaluation of boné mineral } \\
\text { density in postmenopausal } \\
\text { women with alterations of the } \\
\text { mandible cortical bone. }\end{array}$ & $\begin{array}{l}\text { A identificação precoce de mulheres com o risco aumentado para fratura devido à presença de } \\
\text { osteoporose é importante pois, a eficácia diagnóstica das medidas corticais da mandíbula na } \\
\text { identificação de baixa densidade mineral óssea e outros métodos de imagem como a } \\
\text { radiografia panorâmica, fornecem informações suficientes para fazer um rápido diagnóstico e } \\
\text { tratamento. }\end{array}$ \\
\hline $\begin{array}{l}\text { PAVLESEN et al., } \\
2016 .\end{array}$ & 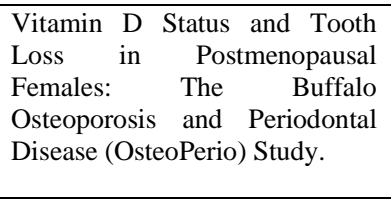 & $\begin{array}{l}\text { Nenhuma associação estatisticamente significativa foi observada entre os níveis de vitamina } \mathrm{D} \\
\text { e a história ou incidência de perda dentária por doença periodontal. Um aumento nas chances } \\
\text { de história de perda dentária atribuível à cárie foi observado com concentrações crescentes de } \\
\text { vitamina } D \text {, mas não foi confirmado em análises prospectivas. Nesta coorte de mulheres na } \\
\text { pós-menopausa, os dados não apoiam uma associação entre o status de vitamina D e a perda } \\
\text { dentária. }\end{array}$ \\
\hline $\begin{array}{l}\text { WANG \& } \\
\text { MCCAULEY, } \\
2016 .\end{array}$ & Osteoporosis and Periodontitis. & $\begin{array}{l}\text { A osteoporose e a periodontite são doenças com reabsorção óssea excessiva. Existem vários } \\
\text { fatores de risco compartilhados e seu impacto interativo está surgindo. Estudos clínicos bem } \\
\text { controlados são necessários para estabelecer uma base de evidências para o manejo } \\
\text { interdisciplinar eficiente de ambas as doenças. }\end{array}$ \\
\hline $\begin{array}{l}\text { GOYAL, GOYAL } \\
\& \text { GUPTA, } 2017 .\end{array}$ & $\begin{array}{l}\text { Osteoporosis and Periodontitis } \\
\text { in Postmenopausal Women: A } \\
\text { Systematic Review. }\end{array}$ & $\begin{array}{l}\text { Uma forte associação entre periodontite e osteoporose foi confirmada. Mais estudos } \\
\text { prospectivos baseados na comunidade são necessários para justificar a força dessa associação. }\end{array}$ \\
\hline $\begin{array}{l}\text { KAPOOR et al., } \\
2017 .\end{array}$ & $\begin{array}{l}\text { Association between Dental } \\
\text { Health and Osteoporosis: A } \\
\text { Study in South Indian } \\
\text { Postmenopausal Women }\end{array}$ & $\begin{array}{l}\text { Mulheres pós-menopausadas com osteoporose tiveram um número significativamente maior } \\
\text { de perdas dentárias. A perda dentária pode, portanto, ser usada como um marcador substituto } \\
\text { para prever a osteoporose. }\end{array}$ \\
\hline $\begin{array}{l}\text { SALES, CATÃO } \\
\& \text { NETO, } 2017 .\end{array}$ & $\begin{array}{l}\text { Condições de saúde bucal do } \\
\text { idoso no Brasil: uma revisão de } \\
\text { literatura. }\end{array}$ & $\begin{array}{l}\text { Observou-se a necessidade de um tratamento odontológico voltado para a população idosa, } \\
\text { devido às patologias oriundas da idade. O conhecimento dessas patologias permite que os } \\
\text { profissionais de saúde trabalhem com a promoção de saúde e prevenção dos agravos. }\end{array}$ \\
\hline TOUNTA, 2017. & $\begin{array}{l}\text { Diagnosis of osteoporosis in } \\
\text { dental patients. }\end{array}$ & $\begin{array}{l}\text { O dentista tem um papel no rastreamento da osteoporose ainda não diagnosticada. O principal } \\
\text { contribuinte para o rastreamento de baixa densidade mineral óssea é a radiografia panorâmica. } \\
\text { No entanto, frequentemente os raios-X são de baixa qualidade, devido ao uso de equipamentos } \\
\text { desatualizados ou mau posicionamento do paciente. É aconselhável um treinamento especial } \\
\text { aos dentistas, no que diz respeito ao rastreamento da osteoporose em pacientes odontológicos, } \\
\text { bem como sua maior familiarização com a prática de raios-X digital. }\end{array}$ \\
\hline $\begin{array}{l}\text { JAGELAVICIENE } \\
\text { et al., } 2018 .\end{array}$ & $\begin{array}{l}\text { The Relationship between } \\
\text { Vitamin D and Periodontal } \\
\text { Pathology. }\end{array}$ & $\begin{array}{l}\text { O artigo avaliou a importância da Vitamina } \mathrm{D} \text { na patogênese de doenças periodontais, ele } \\
\text { analisa a fisiopatologia da doença através do mecanismo imunomodulador da vitamina em } \\
\text { relação a densidade mineral óssea, absorção óssea e reação imunológica (combate a antígenos } \\
\text { causadores de doenças periodontais). }\end{array}$ \\
\hline $\begin{array}{l}\text { MEIRA et al., } \\
2018 .\end{array}$ & $\begin{array}{l}\text { Multidisciplinaridade no } \\
\text { cuidado e atenção à saúde bucal } \\
\text { do idoso. }\end{array}$ & $\begin{array}{l}\text { A abordagem multiprofissional no atendimento à pessoa idosa, contempla tanto ações } \\
\text { preventivas, como o diagnóstico precoce de lesões bucais, quanto intervenções curativas e } \\
\text { reabilitadoras, que contribuam na melhoria da qualidade de vida, com respaldo no } \\
\text { conhecimento científico sobre o cuidado e atenção à saúde bucal dessa população. }\end{array}$ \\
\hline $\begin{array}{l}\text { VARGAS et al., } \\
2018 .\end{array}$ & $\begin{array}{l}\text { Os efeitos da Osteoporose na } \\
\text { cavidade bucal e a contribuição } \\
\text { do Cirurgião-Dentista: Revisão } \\
\text { de literatura. }\end{array}$ & $\begin{array}{l}\text { A perda óssea relativa ao osso alveolar possui gravidade e aumenta com a idade sendo } \\
\text { proveniente em parte das condições sistêmicas desfavoráveis que predispõem a osteopenia e a } \\
\text { osteoporose. Conseguindo prevenir ou evitar a ocorrência dessas manifestações sistêmicas } \\
\text { desfavoráveis pode-se retardar a perda óssea alveolar. Estudos estabelecem que a perda } \\
\text { dentária em grupos osteoporóticos é de } 2 \text { a } 4 \text { vezes maior do que no grupo de pacientes não- } \\
\text { osteoporóticos. }\end{array}$ \\
\hline $\begin{array}{l}\text { ALAM et al., } \\
2020 .\end{array}$ & $\begin{array}{l}\text { Evaluation of Clinical and } \\
\text { Radiographic Parameter as } \\
\text { Dental Indicators for } \\
\text { Postmenopausal Osteoporosis. } \\
\end{array}$ & $\begin{array}{l}\text { Os achados do índice cortical mandibular (MCI) na radiografia panorâmica são indicadores } \\
\text { eficazes de alterações ósseas na osteoporose pós-menopausa, determinando assim a predição } \\
\text { precoce do risco de fratura osteoporótica e reduzindo sua morbidade. }\end{array}$ \\
\hline $\begin{array}{l}\text { IZUORA et al., } \\
2020 .\end{array}$ & $\begin{array}{l}\text { Relationship Between Oral } \\
\text { Health and } \quad \text { Clinical } \\
\text { Osteoporosis } \\
\text { Hospitalized Patients eith and } \\
\text { Without-Diabetes. }\end{array}$ & $\begin{array}{l}\text { O Diabetes Mellitus é um fator de risco para Osteoporose e também está associado a maior } \\
\text { prevalência de doença periodontal. A perda de dente está associada a problemas de saúde } \\
\text { bucal, osteoporose e diabetes. Ambos compartilham de fatores de riscos comuns: idade } \\
\text { avançada, inflamaçãa, tabagismo e estresse. Embora exista na literatura relação entre } \\
\text { osteoporose e diabetes, neste estudo não foi encontrada associação significativa entre ambas. } \\
\text { Vale ressaltar que os pacientes avaliados não tinham a idade muito avançada, o que influencia } \\
\text { nos pacientes avaliados com osteoporose. }\end{array}$ \\
\hline SEN et al., 2020. & $\begin{array}{l}\text { Disinfecting effects of rotary } \\
\text { instrumentation with either } \\
2.5 \% \text { sodium hypochlorite or } \\
2 \% \text { chlorhexidine as the main } \\
\text { irrigant: a randomized clinical } \\
\text { study. }\end{array}$ & $\begin{array}{l}\text { A menopausa é uma fase fisiológica da mulher, que implica em alterações na quantidade e } \\
\text { viscosidade da saliva, alterações no controle de bactérias e placas, contribuindo para o risco } \\
\text { aumentado de infecções. Além disso, o artigo traz a osteoporose como uma das consequências } \\
\text { da menopausa. Por isso, as principais manifestações clínicas nessa população são: } \\
\text { xerostosmia, síndrome da boca ardente, periodontite, gengivite, neuralgia do trigemio, } \\
\text { distúrbios de mucosa e osteoporose. }\end{array}$ \\
\hline $\begin{array}{l}\text { TANAKA et al., } \\
2020 .\end{array}$ & $\begin{array}{l}\text { Mandibular Radiomorphometric } \\
\text { Indices and Tooth Loss as } \\
\text { Predictors for the Risk of } \\
\text { Osteoporosis using Panoramic } \\
\text { Radiographs. }\end{array}$ & $\begin{array}{l}\text { Idade e perda dentária estiveram relacionadas a largura do córtex mandibular e com o córtex } \\
\text { mandibular inferior na população investigada. Uma idade } \geq 60 \text {, bem como mais de } 3,5 \text { dentes } \\
\text { perdidos, parecem ser indicadores de risco de osteoporose em mulheres chinesas com base em } \\
\text { vistas panorâmicas usando software baseado em inteligência artificial. }\end{array}$ \\
\hline
\end{tabular}




\begin{tabular}{|c|c|c|}
\hline $\begin{array}{l}\text { JONASSON, } \\
\text { HASSANI- } \\
\text { NEJAD } \quad \& \\
\text { HAKEBERG, } \\
2021 .\end{array}$ & $\begin{array}{l}\text { Mandibular cortical bone } \\
\text { structure as risk indicator in } \\
\text { fractured and non-fractured 80- } \\
\text { year-old men and women. }\end{array}$ & $\begin{array}{l}\text { No presente estudo foi realizada a investigação, sendo encontradas diferenças significativas } \\
\text { entre homens e mulheres em relação à espessura cortical e erosão. Um córtex normal (MCI1) } \\
\text { foi encontrado em } 65 \% \text { dos homens e } 26 \% \text { das mulheres, enquanto } 41 \% \text { das mulheres e } \\
\text { apenas } 7 \% \text { dos homens tinham um córtex gravemente erodido. Os parâmetros corticais podem } \\
\text { ser usados como marcadores de risco para fratura entre as mulheres idosas. Grandes estudos } \\
\text { longitudinais são necessários antes que possa ser determinado se os mesmos parâmetros } \\
\text { corticais podem ser usados para homens idosos, ou se outras circunstâncias são mais } \\
\text { importantes. }\end{array}$ \\
\hline $\begin{array}{l}\text { TWARDOWSKI } \\
\text { et al., } 2021 .\end{array}$ & $\begin{array}{l}\text { Plasma 25-Hydroxyvitamin D } \\
\text { Concentrations and Serum and } \\
\text { Salivary C-Reactive Protein in } \\
\text { the Osteoporosis and } \\
\text { Periodontal Disease Study. }\end{array}$ & $\begin{array}{l}\text { A vitamina D desempenha um papel importante na prevenção do desenvolvimento e } \\
\text { progressão da doença periodontal, mas os mecanismos imunomoduladores subjacentes } \\
\text { permanecem pouco estudados. Foi examinado a associação transversal entre os biomarcadores } \\
\text { do status da vitamina D e da proteína C reativa (PCR) entre as mulheres na pós-menopausa } \\
\text { com idades entre 53-81 anos. Uma associação inversa foi observada entre } 25 \text {-(OH) D e PCR } \\
\text { salivar em um modelo para idade, tabagismo, frequência de escovação, uso de fio dental e uso } \\
\text { de terapia hormonal. Não foi encontrada relação entre } 25(\mathrm{OH}) \mathrm{D} \text { e PCR sérica. }\end{array}$ \\
\hline
\end{tabular}

Fonte: Autores (2021).

\section{Discussão}

Todos os estudos que compreendem essa revisão analisaram a relação da doença periodontal com os fatores relacionados à osteoporose. Entretanto, há uma escassez em trabalhos que abordem esse tema o que limitou este estudo. De acordo com Vargas et al. (2018) durante o envelhecimento todas as estruturas do corpo são afetadas, não sendo diferente com a cavidade oral. Os efeitos da doença na cavidade bucal são representados pela redução do rebordo alveolar, diminuição da massa e densidade óssea maxilar, diminuição da espessura óssea cortical observada pelo aumento da porosidade cortical da mandíbula, diminuição da vascularização, redução da capacidade de cicatrização e o edentulismo. Sendo assim, nos ossos maxilares ocorre tanto a osteopenia quanto a osteoporose devido à perda de massa óssea do processo alveolar (Vargas et al., 2018; Goyal, Goyal \& Gupta, 2017; Jonasson, Hassani-Najed \& Hakeberg, 2021).

A osteoporose em âmbito bucal manifesta-se partindo de um quadro sistêmico de comprometimento do paciente. Segundo, Vargas e colaboradores (2018), estudos demonstram a relação entre a densidade óssea da mandíbula com o restante do esqueleto: a perda óssea do quadril, punho e áreas lombares, estão correlacionadas com a baixa densidade óssea na mandíbula. Nesse contexto, diversos artigos comprovam a relação da perda óssea mineral generalizada no esqueleto contribuindo para as perdas dentárias em grupos osteoporóticos (Vargas et al., 2018; Miliuniene et al., 2016; Alam et al., 2020).

O risco para perda dentária em grupos osteoporóticos é de 2 a 4 vezes maior quando comparados a pacientes não osteoporóticos (Vargas et al., 2018). Visualizando os riscos dos pacientes osteoporóticos se faz necessário entender sobre o desenvolvimento da doença a fim de atingir o mecanismo fisiopatológico e minimizar as suas repercussões. Alguns artigos abordaram indiretamente a osteoporose através desses fatores de risco, sendo eles: mulheres menopausadas, diabetes mellitus e a deficiência de vitamina D (Jagelaviciene et al., 2018; Sen et al., 2020; Izuora et al., 2020; Wang \& McCauley, 2016; Tanaka et al., 2020).

Segundo, Sen et al. (2020) as principais manifestações clínicas em mulheres menopausadas são a xerostomia, síndrome da boca ardente, periodontite, gengivite, neuralgia do trigêmeo, distúrbios de mucosa e a osteoporose. A explicação para isso se dá através da baixa produção de estrogênio após a menopausa, estimulando a produção de substâncias inflamatórias (interleucinas, fator de necrose tumoral alfa, granulócitos, fator estimulador de colônias, etc.) e, posteriormente, a produção de osteoclastos maduros que induz a reabsorção do osso esquelético e alveolar. Diante disso, as mulheres menopausadas encontram-se com a densidade mineral óssea diminuída e o risco de perda de dente aumentado em quatro vezes quando comparadas a mulheres saudáveis, e três vezes se comparadas a mulheres com um grau de osteopenia (Wang \& McCauley, 2016; Goyal, Goyal \& Gupta, 2017; Miliuniene et al., 2016; Alam et al., 2020; Kapoor et al., 2017).

No entanto, além da perda óssea se houver associação com a presença de antígenos (placas bacterianas, biofilmes, toxinas) a reação inflamatória é ainda mais exacerbada, estimulando cada vez mais os osteoclastos, comprometendo o quadro 
clínico. Sendo assim, a resposta inflamatória inicia a cascata que pode levar a ativação constante de proteinases e enzimas digestivas do tecido, levando a destruição do tecido conjuntivo, alveolar, reabsorção óssea e perda dentária. Mesmo na presença da doença osteoporótica o principal fator de risco para o desenvolvimento de periodontite em mulheres menopausadas é a presença da placa bacteriana (Sen et al., 2020; Goyal, Goyal \& Gupta, 2017; Miliuniene et al., 2016).

Outro fator de risco encontrado é a presença do Diabetes Mellitus que também está associado à doença periodontal e perda de dente. Apesar de compartilharem fatores de riscos em comum (inflamação, idade avançada, tabagismo e estresse) há estudos que associam ambas patologias. No entanto, o trabalho de Izuora et al. (2020) não encontrou nenhuma associação significativa entre a Osteoporose e a presença do Diabetes Mellitus.

Por fim, o colecalciferol, também conhecido como vitamina D, um pró-hormônio responsável pelo mecanismo imunomodulador em relação à densidade mineral óssea, absorção e reação imunológica (combatendo os antígenos causadores de doenças periodontais). Durante todo o processo inflamatório a vitamina D é responsável por ativar a síntese de proteínas necessárias para a agregação e junções desmossômicas epiteliais, combatendo a invasão de placas bacterianas, evitando inflamação do tecido periodontal, reabsorção e perda do dente (Jagelaciviene et al., 2018; Kapoor et al., 2017; Twardowski et al., 2021). Apesar do seu mecanismo imunológico conhecido, o estudo de Pavlesen et al. (2016) não observou diferença entre os grupos de pacientes com níveis normais e deficientes de vitamina $\mathrm{D}$ em relação aos problemas periodontais, perda de dente e cárie (Pavlesen et al., 2016).

O osso mandibular é um dos quatro tecidos que formam o periodonto, por isso em caso de doenças como osteoporose, a densidade mineral óssea diminui em todos os ossos, incluindo no osso maxilar, onde aumenta a reabsorção do rebordo alveolar e a perda dentária (Jagelaciviene et al., 2018; Tanaka et al., 2020). A concentração ideal de colecalciferol para o tecido periodontal é de aproximadamente $90-100 \mathrm{nmol} / \mathrm{L}$ e concentrações mais baixas estão associadas à progressão da doença e perda dentária (Jagelaciviene et al., 2018).

Apesar dos fatores relacionados à saúde bucal nos idosos estarem entrelaçados com o desenvolvimento ou agravamento do quadro osteoporótico, estudos mais precisos devem ser elaborados para melhor elucidação do mecanismo patológico da doença na cavidade oral.

\section{Conclusão}

A análise da etiopatogenia da Osteoporose e seus impactos com a Saúde Bucal em pacientes idosos é de extrema importância, posto que, nesta revisão foram identificados os principais fatores de riscos para as repercussões orais da doença. Ressalta-se que, a saúde pública oral é precária quando referida a população geriátrica e o reconhecimento dessas variáveis pelo cirurgião-dentista viabiliza a identificação e o manejo correto desses indivíduos. Sendo assim, é extremamente necessário que se realize estudos populacionais a longo prazo, com adequado acompanhamento, afim de identificar maiores relações da Osteoporose com as alterações provenientes da idade e com as mudanças patológicas da doença: Osteoporose. Além disso, é necessário observar a o envolvimento dos fatores de riscos com a fisiopatologia da doença e a sua repercussão no longo prazo. Por fim, conclui-se que é necessário identificar os fatores que predispõem a um risco aumentado para atuar de modo preventivo com a finalidade de se obter desfechos clínicos positivos.

\section{Referências}

Alam, T., AlShahrani, I., Assiri, K. I., Almoammar, A., Togoo, R. A., Lugman, M. (2020). Evaluation of Clinical and Radiographic Parameter as Dental Indicators for Postmenopausal Osteoporosis. Oral Health Prev Dent 18 (1), 499-504. https://www.quintessence-publishing.com/deu/en/articledownload/842324/oral-health-and-preventive-dentistry/2020/01/evaluation-of-clinical-and-radiographic-parameters-as-dental-indicators-for-postmenopausalosteoporosis 
Associação Brasileira de Avaliação óssea e Osteometabolismo. (2020). Juntos pelo Dia Mundial de Combate à Osteoporose. ABRASSO. https://abrasso.org.br/dia-mundial-de-combate-a-osteoporose/

Gil, A. C. (2010). Como elaborar projetos de pesquisa. Atlas. https://docero.com.br/doc/s818e5

Goyal, L., Goyal, T. \& Gupta, N. D. (2017). Osteoporosis and Periodontitis in Postmenopausal Women: A Systematic Review. J Midlife Health 8 (4), 151158. https://www.ncbi.nlm.nih.gov/pmc/articles/PMC5753494/

Izuora, K., Allenback, G., Champion, A., Gewelber, C., \& Neubauer, M. (2020). Relationship Between Oral Health and Clinical Osteoporosis Among Hospitalized Patients with and Without Diabetes. Cureus 12 (2), 1-8. https://www.ncbi.nlm.nih.gov/pmc/articles/PMC7105262/

Jagelaviciene, E., Vaitkeviciene, I., Silingaite, D., Sinkunaite, E., \& Daugelaite, G. (2018). The relationship between vitamin D and periodontal pathology. Medicina (Kaunas) 24 (45): 1-8. https://www.ncbi.nlm.nih.gov/pmc/articles/PMC6122115/

Jonasson, G., \& Rythén, M. (2016). Alveolar bone loss in osteoporosis: a loaded and cellular affair?. Clin Cosmet Investig Dent. 13 (8), 95-103. https://www.ncbi.nlm.nih.gov/pmc/articles/PMC4948717/

Jonasson, G., Hassani-Nejad A., \& Hakeberg, M. (2021). Mandibular cortical bone structure as risk indicator in fractured and non-fractured 80-year-old men and women. BMC Oral Health 21 (1), 468. https://www.ncbi.nlm.nih.gov/pmc/articles/PMC8461912/

Kapoor, N., Cherian K. E., Pramanik, B. K., Govind, S., Winford M. E., Shetty, S., Thomas, N., \& Paula, T. V. (2017). Association between Dental Health and Osteoporosis: A Study in South Indian Postmenopausal Women. J Midlife Health 8 (4), 159-162. https://www.ncbi.nlm.nih.gov/pmc/articles/PMC5753495/

Meira, I. A., Martins, M. L., Maciel, P. P., Cavalcanti, I. W., Araújo, T. P., \& Piagge, C. S. L. D. (2018). Multidisciplinaridade no cuidado e atenção à saúde bucal do idoso. Rev. Ciênc. Méd 27 (1), 39-45. https://seer.sis.puc-campinas.edu.br/seer/index.php/cienciasmedicas/article/view/3949/2661

Miliuniene, E., Alekna, V., Peciuliene, V., \& Tamulaitiene, M. (2016). Evaluation of boné mineral density in postmenopausal women with alterations of the mandible cortical bone. Stomatologija 18 (3), 86-91. Recuperado dehttps://sbdmj.1smuni.lt/163/163-03.pdf

Pavlesen, S., Mai, X., Wactawaski-Wende, J., LaMonte, M. J., Hovey, K. M., Genco, R. J., \& Millen, A. E. (2016). Vitamin D Status and Tooth Loss in Postmenopausal Females: The Buffalo Osteoporosis and Periodontal Disease (OsteoPerio) Study. J Periodontol 87 (8), 852-63. https://www.ncbi.nlm.nih.gov/pmc/articles/PMC4966999/

Sales, M. V. G., Catão, M. H. C. V., \& Neto, J. A. F. (2017). Condições de saúde bucal do idoso no Brasil: uma revisão de literatura. Arch Health Invest 6 (3), 120-124. https://archhealthinvestigation.com.br/ArcHI/article/view/1918/pdf

Sen, S., Sen, S., Dutta, A., Abhinandan, Kumar, V., \& Singh, A. K. (2020). Oral manifestation and its management in postmenopausal women: na integrated review. Menopause Rev 19 (2), 101-103. https://www.ncbi.nlm.nih.gov/pmc/articles/PMC7422290/

Spezzia, S. (2013). Saúde bucal em idosos com osteoporose relato de casos. Rev UNINGÁ 16 (1), 64-69. https://www.mastereditora.com.br/periodico/20130929_160947.pdf

Spezzia, S. (2014). O papel da osteoporose na odontologia. Rev Assoc Paul Cir Dent 68 (4), 366-7. http://revodonto.bvsalud.org/scielo.php?script=sci_pdf\&pid=S0004-52762014000400016\&lng=pt\&nrm=iso\&tlng=pt

Tanaka, R., Tanaka, T., Yeung, A. W. K., Taguchi, A., Katsumata A., \& Bomstein M. M. (2020). Mandibular Radiomorphometric Indices and Tooth Loss as Predictors for the Risk of Osteoporosis using Panoramic Radiographs. Oral Health Prev Dent. 18 (1), 773-782. https://www.quintessencepublishing.com/deu/en/article-download/842356/oral-health-and-preventive-dentistry/2020/01/mandibular-radiomorphometric-indices-and-tooth-loss-aspredictors-for-the-risk-of-osteoporosis-using-panoramic-radiographs

Tounta, T. S. (2017). Diagnosis of osteoporosis in dental patients. Review J Frailty Sarcopenia Falls 2 (2), $21-27$. https://www.ncbi.nlm.nih.gov/pmc/articles/PMC7155378/

Twardowski, S. E., Wactawski-Wende, J., Hovey, K. M., Andrews, C. A., Banack, H. R., LaMonte, M. J., \& Millen, A. E. (2021). Plasma 25-Hydroxyvitamin D Concentrations and Serum and Salivary C-Reactive Protein in the Osteoporosis and Periodontal Disease Study. Nutrients 13 (4), 1148. https://www.ncbi.nlm.nih.gov/pmc/articles/PMC8067277/

Vargas, R. M., Schmitt, E. A., Rodrigues, R. B. L., Flores, J. A., Romano, G., \& Flores, F. W. (2018). Os efeitos da osteoporose na cavidade bucal e a contribuição do cirurgião dentista: revisão de literatura. Revista Hígia 3 (1): 14-27. http://fasb.edu.br/revista/index.php/higia/article/view/219/233

Wang, C. W. J., \& McCauley, L. K. (2016). Osteoporosis and Periodontitis. Curr Osteoporos Rep. 14 (6), 284-291. https://www.ncbi.nlm.nih.gov/pmc/articles/PMC5654540/ 